\title{
Autismo: a discussão de um paradoxo?
}

\section{Autism: the discussion of a paradox?}

\section{Aliny Lamoglia de Carvalho*}

Universidade Federal do Estado do Rio de Janeiro-UNIRIO, Rio de Janeiro, RJ, Brasil

\begin{abstract}
RESUMO
O artigo apresenta uma discussão sobre as mudanças de paradigmas acerca do autismo infantil. A partir de um artigo publicado em uma revista de circulação internacional, apresentam-se as descobertas da sociogenética sobre as bases neurobiológicas do autismo e sua vinculação com critérios diagnósticos dos Transtornos Invasivos do Desenvolvimento propostos pelo DSM IV. Algumas contribuições de autores contemporâneos são trazidas para fomentar a discussão e também algumas perspectivas de psicanalistas que já no século passado apontavam para um posicionamento no qual a psicanálise talvez não representasse o melhor referencial teórico para a discussão da síndrome do autismo infantil.
\end{abstract}

Palavras-chave: Autismo, Psicanálise, Sociogenética.

\begin{abstract}
The article presents a discussion about the paradigm shifts of infantile autism. From an article published in a magazine of international circulation, the findings of sociogenetic about the neurobiological basis of autism and its link with the diagnostic criteria for Pervasive Developmental Disorders proposed by DSM IV are presented. Some contributions from contemporary authors are brought to foster discussion and also some prospect of psychoanalysts who have in the last century pointed to a position in which psychoanalysis may not represent the best theoretical framework for the discussion of the syndrome of infantile autism.
\end{abstract}

Keywords: Autism, Psychoanalysis, Sociogenetic.

\section{I ntrodução}

O título das linhas que seguem poderia ser "Como ousar um caminho", tal a minha impressão sobre o que ainda há por descobrir acerca do autismo. A curiosidade, porém, e as questões lingüísticas envolvidas neste quadro de Transtorno Invasivo do Desenvolvimento muito me instigam e fazem pensar sobre as tentativas de explicação que, vez ou outra, encontro na mídia ou mesmo em trabalhos científicos.

\footnotetext{
"As tentativas de desdobrar uma descrição dinâmica da plasticidade no nível da função neurológica fazem eco à asserção de Tomasello (1999) a respeito do material genético na evolução cognitiva humana. Seu argumento é que dicotomias como "nature-nurture" (natureza-educação),
} 
que estruturam lingüisticamente grande parte do debate, estão ultrapassadas. (...) Tomasello, Dennett, Clark e Damasio, cada um a seu modo, apontam um novo desdobramento, que oferece novas concepções do papel da biologia no desenvolvimento do pensamento. Os estágios iniciais desse desdobramento sugerem alto grau de compatibilidade com uma explanação sociogenética do desenvolvimento" (DANIELS, 2003, p. 66).

A citação acima reúne, a um só tempo, quatro autores contemporâneos que têm fomentado o debate sobre as origens culturais do conhecimento humano e com os quais venho dialogando já há algum tempo. Quando a li, considerei-a um "serendipismo", nome que dão os poetas àquilo que encontramos quando não o estamos buscando. Também experimentei um forte sentimento de que minhas investigações assistemáticas na prática clínica psicopedagógica com crianças autistas pareciam encontrar eco nas valiosas contribuições destes autores às questões sobre 0 desenvolvimento humano inicial. Por tê-la encontrado, portanto, resolvi ensaiar estas linhas, um début sobre autismo, à luz da teoria sociogenética, que ora apresento.

\section{A discussão}

A idéia inicial do presente artigo é discutir algumas considerações acerca do autismo infantil que comumente ocupam as páginas de periódicos sobre psicologia, educação ou áreas afins.

O artigo de Pires (2007), publicado na revista Mente \& Cérebro (Novembro/2007) traz, à luz das idéias dos psicanalistas Guedeney e Lebovici (1999), o autismo infantil como um segundo paradigma para o funcionamento da mente humana, depois do Complexo de Édipo.

Um paradigma, por definição, é um modelo teórico explicativo para um fenômeno humano ou da natureza, aceito em determinados tempo e espaço. Não compreendi, ao ler a referida matéria, como comparar um constructo teórico, como é o caso do Complexo de Édipo, a um diagnóstico clínico, como é o caso do autismo infantil, classificado desde 1998 pelo CID 10 (Classificação Internacional de Doenças, WHO, 1998) e pelo DSM-IV-TR (Diagnostic and Statistical Manual of Mental Disorders) desde 2002.

O conceito cunhado por Freud (1910/1981), é metafórico e "efetua-se (...) no decorrer da sua auto-análise, que o leva a reconhecer em si o amor pela mãe e, para com o pai, um ciúme em conflito com a afeição que the dedica" (LAPLANCHE; PONTALIS, 1986, p. 117). Como qualquer constructo teórico, o conceito de "Complexo de Édipo" dependeu da aceitação da comunidade científica, de condicionantes sócio-históricas e culturais, por fim, dependeu do uso de uma língua que o avalizou. Por sua vez, o uso de critérios diagnósticos objetivos para o autismo possui como prerrogativa o fato de considerá-lo um 
"transtorno do desenvolvimento com base biológica inata" (LAMPREIA; LIMA, 2008) e deve possibilitar que profissionais em quaisquer partes do mundo sejam capazes de diagnosticar a síndrome do autismo infantil a partir de uma investigação comportamental que contemple os seguintes critérios: 1) Comprometimento qualitativo da interação social; 2) Comprometimento qualitativo da comunicação e 3) Padrões restritos e repetitivos de comportamento, interesses e atividades. Estes três grupos de critérios diagnósticos subdividem-se, por sua vez, em 12 itens e podem ser visualizados no DSM-IV-TR (Diagnostic and Statistical Manual of Mental Disorders).

A epígrafe que apresenta o artigo referido anteriormente traz a seguinte afirmação: "Seres humanos têm disposição inata para relacionamentos e comunicação: somos sensíveis às expressões faciais, reagimos a elas. Nas crianças autistas, no entanto, algo falha nesse contato inicial". Estas palavras iniciais nos induzem a pensar em uma consonância com as idéias recentes da abordagem sociogenética (TOMASELLO, 2003, entre outros autores), que preconiza a existência de um dispositivo inato para a interação. Apesar disto, as construções com base em uma explicação psicanalítica apresentadas a seguir no artigo contrariam tal afirmação, como, por exemplo, “o autismo denuncia a necessidade de construção prévia, já que é uma condição em que, justamente, esse desenvolvimento fracassa e a fusão, a reciprocidade e comunicação mútua não ocorrem" ( $p$. 75). Na concepção sociogenética, a reciprocidade e a interação ocorrem como conseqüência do somatório de um relacionamento entre a criança e o adulto e a base inata para a interação com a qual o bebê nasceu. Compreendendo-se aqui como "relacionamento entre criança e adulto" toda a complexa rede de cuidados e respostas às necessidades essenciais das crianças tal como apontada por Brazelton e Greenspan (2002). A interação é, portanto, condição prévia para a sobrevivência do bebê humano que, dentre todos os mamíferos, é o mais imaturo ao nascer, mas ela sozinha não promove o desenvolvimento. Estas interações precoces se dão justo por não haver obstáculo orgânico que impeça a criança de usufruir do contato com o adulto e, daí, aprender o uso social do olhar, do sorriso, das expressões faciais, das vocalizações - todos estes considerados precursores não-verbais do desenvolvimento - e de tudo o mais que se seguirá. Relatos de pessoas que nasceram cegas indicam que até mesmo o direcionamento da face para a pessoa que fala deve ser sistematicamente ensinado, do contrário, a pessoa cega tenderá a direcionar o ouvido à fonte sonora, o que para o universo das pessoas que enxergam pode dar a impressão de desatenção ou desconsideração por quem fala. As expressões faciais também são aprendidas socialmente e nos casos de cegueira 
congênita ou precoce, precisam ser sistematicamente ensinadas às crianças (VEIGA, 1983).

O artigo traz ainda a expressão "falha no contato inicial entre a mãe e o bebê". Não fica claro, porém, se a "disposição inata para relacionamentos" se refere ao "dispositivo" inato para a interação. Neste caso, novamente, pareceria estar de acordo com o que afirma Tomasello (2003):

\begin{abstract}
“Em relação a isso vale notar (...) que, na ontogênese humana existe uma síndrome muito específica decorrente de causas biológicas - o autismo -, na qual os indivíduos mais gravemente afetados são incapazes tanto de compreender as outras pessoas como agentes mentais/intencionais iguais a eles mesmos, como também de se envolver em habilidades de aprendizagem cultural típicas da espécie" (HOBSON, 1993; BARON-COHEN, 1993; SIGMAN; CAPPS, 1997; CARPENTER; TOMASELLO, p. 8).
\end{abstract}

Se se trata, por outro lado, de inadequações no contato inicial da díade mãe/bebê seria necessário considerar uma leitura intencional do bebê ainda mais precoce do que as habilidades que os estudos sociopragmáticos já nos revelam. Tais habilidades incluem, nos primórdios da ontogênese, a leitura intencional, isto é, "a criança acaba percebendo a si mesma como um agente intencional - ou seja, um ser cujas estratégias comportamentais e de atenção são organizadas em função de metas -, e por isso ela automaticamente vê os outros seres com quem se identifica da mesma maneira" (TOMASELLO, 2003, p.19). E esta habilidade acontece, surpreendentemente, por volta dos oito ou nove meses de vida. Citarei algumas outras habilidades a seguir.

Para as abordagens sociocognitivistas do funcionamento psíquico, nas fases iniciais do desenvolvimento humano, "construção prévia" é algo que já estava presente nas palavras de Vygotsky ([1939]1993), e que constituiria ontogeneticamente os seres humanos, ou seja, na raiz do social, estaria o "instinto". Vygotsky esperava garantir, com esta afirmação, uma predisposição específica da criança em relação ao outro da espécie e assegurar a possibilidade tanto da mediação social quanto da comunicação como funções primitivas da linguagem (LIER-DE VITTO, 1998).

Ainda sobre a situação da criança autista, Tomasello (2003) acrescenta:

\footnotetext{
“Crianças autistas (...) crescem no meio de produtos culturais cumulativos mas não são capazes de tirar vantagem da sabedoria coletiva expressa neles porque, por razões biológicas, não possuem as habilidades sociocognitivas necessárias" (p. 10).
} 
Pesquisas recentes com bebês (BRAZELTON, 2002; MOURA, 2004; MOURA; RIBAS, 2005; LAMPREIA; LIMA, 2008) mostram que o direcionamento do olhar, 0 reconhecimento de faces, 0 reconhecimento da voz humana, a capacidade de seguir o apontar, o apontar declarativo, o apontar imperativo e outras competências não são aprendidas a partir da experiência, já que são verificadas sem que nenhum ensino sistemático seja realizado. $O$ simples ato de apontar para um objeto, com o intuito de compartilhar a atenção dedicada a este objeto com alguém é um comportamento exclusivamente humano e a ausência deste comportamento, que se dá, normalmente, muito antes do período em que as primeiras palavras podem ser articuladas, é considerado um importante elemento diagnóstico da síndrome do autismo infantil (Cf. BARONCOHEN et al., 1992).

Outra abordagem, como é o caso da análise do discurso, também aponta para "algo" que já está construído ao nascer, mas que depende necessariamente da relação com o outro. Nas palavras de Lier-De Vitto (1998):

\footnotetext{
“Diante dos monólogos (das crianças) pode-se (...) afirmar que o sujeito nasce no campo da linguagem. É lá que o sujeito se encontra no outro e com ele. Nesse caso, o que conta nesse outro é que ele fala. (...) os monólogos deixam ver sua determinação dialógica e discursiva" (p. 174).
}

Pires (2007) faz referência ao livro citado acima ("Os monólogos da criança - delírios da língua" de Lier-De Vitto) ao concluir que suas crianças dão testemunho de um processo que se instalou nos primeiros momentos de vida, marcado por essa busca-encontro seguida de recolhimento organizador (o grifo é da autora). Seria este "recolhimento organizador" o típico isolamento que vimos em autistas não-verbais? A seguir a autora cita um monólogo de uma das crianças observadas por Lier-De Vitto e conclui: "Nos autistas inacessíveis isso (o "monólogo no berço" ou a fala egocêntrica, na perspectiva de Vygotsky) não se dá". Para a posição teórica que adoto aqui crianças com a síndrome do autismo que não são afetadas pela presença do outro (já que há um espectro de gravidade para o autismo, que vai do não-verbal ao verbal) não podem aprender suas especificidades, entre elas, a sua língua. A análise do discurso, teoria que fundamenta 0 trabalho de Lier-De Vitto, pressupõe a determinação discursiva, logo, pressupõe a presença do outro como estruturante para o desenvolvimento típico e, por dedução, se assim acontece com a criança com desenvolvimento típico, por que seria diferente com a criança que apresenta um transtorno no desenvolvimento? 
De volta ao texto em questão, pergunto: o que significaria, em uma abordagem psicanalítica, ter um processo comunicativo instalado nos primeiros momentos de vida? Como dar-se-ia este processo se o bebê humano necessita tanto da nature quanto da nurture, tal como citado acima por Daniels (2003) para que seu desenvolvimento típico ocorra? Nascermos "equipados" com um dispositivo para a comunicação que é fruto da ontogênese, da mesma forma como nascermos "equipados" para sermos bípedes ou para utilizarmos ferramentas de forma inteligente, já traz uma enorme mudança de perspectiva na discussão corpo-mente e esta mudança traz também muitos problemas. Nas palavras de Damásio (2003): “A verdade é que a solução para o problema mente-corpo ou não é satisfatória, ou não tem sido apresentada satisfatoriamente" (p. 194). E os equívocos veiculados sobre o autismo não têm contribuído para desfazer este problema do qual fala Damásio (op. cit.).

Envolver-se em uma situação de comunicação exige reconhecer o outro como um co-específico, ou seja, como um outro ser da mesma espécie e este é o dispositivo que está ausente na síndrome do autismo infantil. Por mais paradoxal que possa parecer esta afirmação, o homem é biologicamente um ser social.

\footnotetext{
"Sabe-se que as crianças autistas apresentam graves problemas de atenção conjunta(1) e de perspectivação (...) produzem muito poucos gestos declarativos (...) e quase não se envolvem em jogos simbólicos ou faz-de-conta, que, em muitos casos, implicam assumir o papel do outro. (...) Algumas crianças autistas com bom desempenho conseguem acompanhar o olhar alheio, mas crianças autistas com desempenho mais baixo praticamente não conseguem se acomodar à perspectiva perceptual alheia" (TOMASELLO, 2003, p. 107).
}

Talvez esta colocação de Tomasello (2003) traga luz à pergunta de Pires (2007) "O que falha nos estados autísticos?".

A seguir, o artigo apresenta a seguinte afirmação: "É notório para estudiosos das primeiríssimas relações que bebês vêm "munidos de um dispositivo". Apesar de estar entre aspas e, portanto, indicar que se trata de uma citação literal, a expressão não é atribuída a nenhum autor ou abordagem teórica em desenvolvimento inicial. Outras expressões ainda, como "mapa de navegação" ou "bússolas de navegação", referidas a competências que o bebê demonstra ao nascer não trazem referência aos seus respectivos autores, deixando dúvidas sobre a qual perspectiva teórica o trabalho se refere.

A explicação apresentada pelas abordagens sociocognitivas sobre 0 autismo, já apontadas anteriormente, sugerem um transtorno neurobiológico, no qual estas crianças nasceriam com a ausência do "dispositivo biológico para a interação com seus co-específicos" 
(TOMASELLO, 2003). Sem querer aqui minimizar a complexidade da questão trazida por um Transtorno Invasivo do Desenvolvimento (TID) e suas conseqüências, é necessário encará-lo como um problema biológico na mesma dimensão em que seres humanos apresentam problemas metabólicos, neurológicos, neuroquímicos ou genéticos.

Pires (2007), por sua vez, afirma que a etiologia do autismo pode ser pautada em dois pressupostos:

- O da interdependência do orgânico e do ambiental

- O do valor determinante da relação mãe-bebê

O primeiro pressuposto trazido pela autora, porém, não explicita sobre a compreensão do que está sendo considerado "orgânico", já que em casos severos, quando se fala de autistas não-verbais, a mobilidade da condição mediante intervenções ambientais é muito pequena. Considero aqui como intervenções ambientais os tratamentos especializados, o processo de escolarização, as interações com os cuidadores ou com outras crianças, etc. (TOMASELLO, 2003; CLARK, 1996). Os estudos sociocognitivos apontam para um novo desdobramento, que oferece novas concepções do papel da biologia no desenvolvimento do comportamento humano. Os estágios iniciais deste desenvolvimento sugerem alto grau de compatibilidade com uma explanação sociogenética do desenvolvimento. Para o entendimento do que afirma a autora faltam exemplos do que seriam as "falhas ambientais" que estão relacionadas ao autismo. Não parece razoável que as semelhanças comportamentais descritas a partir da observação de crianças autistas em diferentes partes do mundo possam ser atribuídas a fatores ambientais comuns a contextos de interação tão distintos.

Quanto à segunda suposição teórica - a determinação da relação mãe-bebê - muitos já foram os trabalhos que trataram desta abordagem psicanalítica para o autismo. Espero não enfadar o leitor ao apresentar, somente a título de contraponto, o trecho a seguir.

\footnotetext{
“Existe uma relação direta entre a tendência anti-social e a privação. Isso é conhecido desde longa data pelos especialistas nesta área, mas deve-se predominantemente a John Bowlby o fato de haver hoje um reconhecimento generalizado das relações entre tendência anti-social e a privação emocional, tipicamente no período que vai até a idade em que a criança começa a dar os primeiros passos, entre um e dois anos de idade" (WINNICOTT, 1987, p. 130131).
}

Quando Winnicott (1987) se refere à privação emocional, trata de situações como crianças evacuadas na guerra; perda de um ou de ambos os pais e conseqüente falta de cuidados primários; lar 
incompleto ou a inexistência de um lar, entre outros e a estes fatores deve-se acrescentar como determinante a idade da criança em que teve início a vivência de um ambiente insuficiente, a inteligência da criança e a existência ou não de um diagnóstico psiquiátrico. As situações apontadas pelo autor não deixam dúvidas sobre a insuficiência extrema dos contextos interacionais em questão e não se assemelham em nada com muitos dos contextos interacionais vividos por crianças autistas que pude acompanhar ao longo dos últimos dezessete anos atuando como psicóloga e psicopedagoga clínica.

\section{Considerações finais}

O artigo com o qual procurei dialogar e discutir o autismo afirma que "o aparecimento tanto de traços como de quadros autistas está inteiramente vinculado ao desequilíbrio do encontro entre o agente materno e a criança" já que deste "encontro" resultariam as "condições constitucionais" para se apropriar dos registros simbólicos que entram no jogo do vínculo" (p. 77). Parece-me haver sugestões de que existem condições constitucionais da criança que contribuem para o autismo e também que fatores biológicos estão presentes, mas não fica claro quais são estes fatores e como eles atuam.

Acredito, a partir das pesquisas citadas, que primeiramente é preciso registrar que, de acordo com Bowlby (1988), seria necessário um aparato simbólico que permitisse ao bebê significar as experiências de "desencontro" vivenciadas com sua mãe. E para haver registros simbólicos é necessário haver uma determinada maturidade neurológica, experiências prévias e signos pré-lingüísticos e lingüísticos ao alcance da criança.

Considera-se, no artigo em questão, uma falha orgânica, mas acredita-se que, na matriz do desenvolvimento infantil está o pressuposto da existência do outro. Para acreditar nesta abordagem seria necessário também acreditar em uma capacidade inata do bebê humano que iria além da habilidade de se comunicar com o seu coespecífico (TOMASELLO, 2003), talvez uma capacidade interpretativa deste bebê acerca da ausência extrema e nociva do outro.

"Ou bem não se busca, ou bem não se encontra" (PIRES, 2007, p.77). Colocado nesses termos, o encontro intersubjetivo mãe/bebê perderia a sua característica de equipamento ontogenético defendido pela abordagem sociocognitiva e alcançaria o estatuto de desejo patrimônio psicodinâmico que nem mesmo Freud ousaria admitir que pudesse prescindir da linguagem simbólica, ou seja, da língua.

Os "ajustes" entre mãe e bebê de fato existem e dependem das características individuais, mas se não falamos aqui de graves transtornos de personalidade, não há distração ou hipervigilância maternas que sejam capazes de promover os danos psicológicos encontrados no autismo não-verbal. 
Adiante afirma-se que o encontro mãe-bebê pode ter se dado "de forma traumática e excessiva, deixando restos indigeríveis" (p. 78). Mais uma vez, aqui, não há explicitação sobre o que é considerado traumático ou excessivo e o que significa "restos indigeríveis" na avaliação do comportamento das crianças autistas que foram observadas.

É possível que haja desencontros entre alguma necessidade do bebê e as respostas da mãe. Se não fosse assim, nenhuma falta constituiria o psiquismo humano. Estes desencontros não podem, porém, ser a causa de um Transtorno Invasivo do Desenvolvimento, da mesma forma que vasodilatadores podem precipitar um episódio de enxaqueca, mas não a causam.

A hipótese, aceita por muitos psicanalistas, de que existiria um estágio infantil normal no autismo primitivo para o qual o autismo patológico seria uma regressão, desde o início da década de 1990, com Tustin (1991), no artigo intitulado "A perpetuação de um erro", foi considerada "defeituosa, baseada em premissas incompletas e inacabadas, (...) um vírus que penetrou e distorceu formulações clínicas e teóricas. Tal concepção perpetuou essas distorções e obstruiu comunicações entre pesquisadores" (ibid., p. 63).

Tustin conclui, a partir das pesquisas de Bower (1976), Stern (1977), Fraiberg (1980), Kreisler (1981), Brazelton (1982) e outros, não haver a fase de autismo normal. Segundo a autora, as descobertas sobre as capacidades dos bebês levaram-na a crer que não haveria a "fase do autismo normal". A hipótese de que o "autismo patológico" seria uma fixação na primeira fase do "autismo primitivo normal" deveria ser considerada equivocada. Daí a proposta da psicanalista em passar a utilizar o termo autismo apenas no contexto da psicopatologia.

Vê-se, a partir das reformulações teóricas que vários psicanalistas empreenderam, que as concepções psicanalíticas para o autismo fazem parte do passado. Freud não se ateve ao estudo das capacidades neurológicas do bebê e como um neurologista sempre a frente de seu tempo, seria razoável supor que ele próprio consideraria a concepção desenvolvimentista como um avanço.

As evidências trazidas pelos estudos sobre o autismo a partir da abordagem sociogenética não põem à prova a eficácia da psicanálise, apenas lançam luz sobre a complexidade humana e a necessidade de que diferentes abordagens teóricas coabitem, se puderem compreender que tratam de diferentes formas o mesmo objeto.

Em outras palavras, a neurociência nos apresenta hoje um panorama sobre como o cérebro cria a mente consciente e já se fala em um “inconsciente genómico", nas palavras de Damásio (2010):

“A psicologia reconheceu desde há muito a existência de bases inconscientes do comportamento e tem vindo a 
estudá-las no âmbito do instinto, dos comportamentos automáticos, dos impulsos e motivações. (...) O inconsciente genómico é em parte responsável pela uniformidade que marca uma grande parte do repertório de comportamentos humanos" (p. 342-343).

Impulsos, motivações e sentimentos são, portanto, ao mesmo tempo, resultados das transmissões dos sinais do corpo para o cérebro humano ou razões pelas quais procuramos um psicanalista. Estas últimas, porém, estão relacionadas intrinsecamente aos jogos de linguagem que somos capazes de jogar, subordinados como estamos às regras da língua e à capacidade de nos beneficiarmos do contato com o outro (WITTGENSTEIN, 1994).

Para concluir, lembro que o próprio Freud fez um elogio à poesia ao afirmar que toda vez que pensava ter descortinado algo sobre a alma humana, descobria que um poeta já havia passado por lá antes dele. Suponho que alguém capaz de fazer tal afirmação seria sensível também às descobertas das teorias desenvolvimentistas sobre 0 comportamento humano e, particularmente, sobre a síndrome do autismo infantil.

Temos visto que programas de educação para crianças autistas que consideram o autismo um transtorno neurobiológico que afeta a interação e pautam todas as suas ações na recuperação dessas interações têm alcançado resultados bastante promissores (Kaufman, 1976). Esta é mais uma evidência de que, apesar de haver uma alteração no substrato neurofisiológico destas crianças, é possível, a partir da mediação sistemática e deliberada, interferir no processo de desenvolvimento, promover aprendizagens e garantir um futuro mais pleno e feliz para elas, tal como Vygotsky $(1993,1994)$ nos ensinou.

\section{Referências Bibliográficas}

BARON-COHEN, S.; ALLEN, J.; GILLBERG, C. Can autism be detected at 18 months? The needed, the haystack, and the CHAT. In: British J ournal of Psychiatry, n. 161, p. 839-843, 1992.

BOWER, T. G. R. Perceptual world of the child. Cambridge, Mass.: Harvard University Press, 1976.

BOWLBY, J. Cuidados maternos e saúde mental. São Paulo: Editora Martins Fontes, 1988.

BRAZELTON, T. B. J oint regulation of neonate-parent behavior. In: TRONICK, E. (Ed.), Social interchange in infancy. Baltimore, Md.: University Park Press, 1982.

BRAZELTON, T. B.; Greenspan, S. I. As necessidades essenciais das crianças. Porto Alegre: Artmed Editora, 2002.

CLARK, $H$. Uses of language. Cambridge: Cambridge University Press, 1996. 
DAMÁSIO, A. Em busca de Espinosa: prazer e dor na ciência dos sentimentos. São Paulo: Companhia das Letras, 2004.

- livro da consciência - a construção do cérebro consciente. Maia: Círculo de Leitores, 2010.

DANIELS, H. Vygotsky e a pedagogia. São Paulo: Edições Loyola, 2003.

DSM-IV-R Manual diagnóstico e estatístico de transtornos mentais. Porto Alegre: Artes Médicas, 2002.

FRAIBERG, S. H. Clinical studies in infant mental health: the first year of life. New York: Basic Books, 1980.

FREUD, S. Obras Completas. Madri: Biblioteca Nueva, [1910]1981.

GUEDENEY, A.; Lebovici, S. Intervenções psicoterápicas pais/ bebê. Porto Alegre: Artes Médicas, 1999.

KAUFMAN, B. Son rise. New York: Harper; Row, 1976.

KREISLER, L.; CRAMER, B. Sur les bases cliniques de la psychiatrie du nourrisson. La Psychiatrie de L'Enfant, n. 24, p. 1-15, 1981.

LAMPREI A, C.; LIMA, M. M. R. Instrumento de vigilância precoce do autismo: manual e vídeo. Rio de Janeiro: Editora PUC-Rio; São Paulo: Edições Loyola, 2008.

LAPLANCHE, J.; PONTALIS, J. B. Vocabulário da psicanálise. São Paulo: Editora Martins Fontes, 1986.

LIER-DE VITTTO, M. F. Os monólogos da criança: delírios da língua. São Paulo: EDUC/FAPESP, 1998.

MOURA, M. L. S.; RIBAS, A. F. P. Bebês: ciência para conhecer, afeto para cuidar. Rio de Janeiro: Proclama Editora, 2005.

MOURA, M. L. S. (Org.). O bebê do século XXI e a psicologia em desenvolvimento. São Paulo: Casa do Psicólogo, 2004.

PIRES, L. P. C. A marca do desencontro. Revista Mente e Cérebro. N178, p. 74-79 Nov. 2007. Disponível em: <http://www2.uol.com.br/vivermente/reportagens/a_marca_do_dese ncontro_imprimir.html>.

STERN, $D$. The first relationship: infant and mother. Cambridge, Mass.: Harvard University Press, 1977.

Médicas Editora, 1992.

TOMASELLO, M. As origens culturais da aquisição do conhecimento humano. São Paulo: Editora Martins Fontes, 2003.

TUSTIN, F. A perpetuação de um erro. Letra Freudiana. Rio de J aneiro: Revinter, p. 63-79, [1979]1995.

VEIGA, J. E. O que é ser cego. Rio de Janeiro: José Olimpio, 1983.

VYGOTSKY, L. S. A formação social da mente. São Paulo: Editora Martins Fontes, 1994.

Fontes, 1993.

Pensamento e Linguagem. São Paulo: Editora Martins

WINNICOTT, D. W. Privação e delinquência. São Paulo: Editora Martins Fontes, 1987. 
WITTGENSTEIN, L. I nvestigações filosóficas. Petrópolis: Vozes, 1994.

WORLD HEALTH ORGANIZATION. International classification of diseases. $10^{\text {th }}$ revision. Genebra: WHO, 1998.

\section{Endereço para correspondência}

Aliny Lamoglia de Carvalho

Núcleo de Educação Inclusiva/UNIRIO, Rua Voluntários da Pátria, no 107, Fundos Salas 32 e 33, Botafogo, CEP 22270-000, Rio de Janeiro - RJ, Brasil

Endereço eletrônico: alinylamoglia@gmail.com

Recebido em: 18/06/2010

Reformulado em: 19/10/2010

Aceito para publicação em: 26/10/2010

Acompanhamento do processo editorial: Adriana Benevides Soares

Notas

* Doutora em Psicologia Social pelo PPGPS da Universidade do Estado do Rio de Janeiro - UERJ; Professora adjunta do Departamento de Fundamentos da Educação da Universidade Federal do Estado do Rio de Janeiro - UNIRIO. 